\title{
Frequency and coexistence of the C677T and A1298C polymorphisms of the MTHFR gene in Aures region of Algeria
}

\author{
DJAARA HAYAT ${ }^{1 \vee}$, YAHIA MOULOUD ${ }^{1}$, BOUSSIF ABDELALI ${ }^{2}$ \\ ${ }^{1}$ Biotechnology's Laboratory of the Bioactive Molecules and the Cellular Physiopathology, Department of Biology of Organisms, University of Batna 2 \\ Mustapha Ben Boulaid. 53 Constantine Rd, Fésdis, Batna 05078, Algeria. Tel: +213-663-432376. ”email: djaarahayat@gmail.com \\ ${ }^{2}$ Department of Microbiology and Biochemistry, University of Batna 2 Mustapha Ben Boulaid. Fésdis, Batna, Algeria
}

Manuscript received: 4 May 2018. Revision accepted: 27 May 2018.

\begin{abstract}
Hayat D, Mouloud Y, Abdelali B. 2018. Frequency and coexistence of the C677T and A1298C polymorphisms of the MTHFR gene in Aures region of Algeria. Biodiversitas 19: 1169-1175. The aim of this study was to assess the frequency of the two most common polymorphisms C677T and A 1298C of the methylenetetrahydrofolate reductase (MTHFR) gene, as well as the coexistence of both these genetic variants in healthy subjects from part of the Algerian population (Aures Region). A total of 94 apparently healthy subjects were enrolled in the study group. The frequency of the both investigated genotypes of the both MTHFR gene polymorphisms (C677T and A1298C) was determined by using the Real-Time Polymerase Chain Reaction-Fluorescence Resonance Energy Transfer (Real-Time PCR-FRET) technic. The frequencies of C and T alleles of C677T polymorphism were 127 (67.55\%), 61 (32.45\%), and for CC, CT, and TT genotypes were $44(46.48 \%), 39(41.8 \%)$ and $11(11.70 \%)$ respectively. Regarding the frequencies at position 1298 , for $\mathrm{A}$ and $\mathrm{C}$ alleles were 147 (78.19\%), 41 (21.81\%), and for AA, AC, and CC genotypes were 60 (63.82\%), 27 (28.72\%) and 7 (7.44\%) respectively. Also, our results indicated that no significant differences in the percentage distributions of the $\mathrm{C} 677 \mathrm{~T}(\mathrm{P}=0.518)$ and A1298C $(\mathrm{P}=0.514)$ polymorphisms between males and females carriers. As noted in the findings, the most frequent coexistence of genotypes were 677CT/1298AA (29.78\%), 677CC/1298AA (22.34\%) and 677CC/1298AC (17.02\%\%). The coexistence of 677TT/1298AA (11.70\%), 677CT/1298 AC (11.70\%) and 677CC/1298 CC (7.44\%) genotypes was observed less frequently and for $677 \mathrm{TT} / 1298 \mathrm{AC}, 677 \mathrm{CT} / 1298 \mathrm{CC}, 677 \mathrm{TT} / 1298 \mathrm{CC}$ genotypes, it has been no observed in the studied population. The frequency of MTHFR $677 \mathrm{C}$ and $\mathrm{T}$ alleles were 0.66 and 0.31 , whereas that of MTHFR1298 A and C alleles were 0.77 and 0.21 , respectively. The allelic distributions of the C677T polymorphism remain intermediate in the Aures region (Northeast of Algeria); that support the idea of a north-south gradient. For the A1298C SNP, our funding appears to be lower compared across populations. In addition, the frequency and coexistence of genotypes of the C677T and A 1298C MTHFR gene polymorphisms in the region studied are similar to other ethnic group populations.
\end{abstract}

Keywords: 5,10-Methylenetetrahydrofolate reductase gene, C677T, A1298C SNPs, coexisting genotypes, Real-Time PCR-FRET

\section{INTRODUCTION}

Proper function of the folate cycle is directly linked to optimal human functioning. Plasma folate and vitamin $\mathrm{B}_{12}$ influence homocysteine (Hcy) metabolism as co-substrate and cofactor, respectively (Lim and Heo 2002). Homocysteine is a sulfur-containing amino acid derived from the metabolism of methionine (Malinow 1994).Total homocysteine levels (tHcy) are controlled by remethylation or transsulfuration pathways of methionine, related to folate and vitamin $B_{-6,12}$ (Taguchi et al. 2012). In addition, Plasma levels of homocysteine are influenced by both environmental and genetic factors.

The 5, 10-methylenetetrahydrofolate reductase (MTHFR) is one of the main regulatory enzymes of homocysteine metabolism (Frosst et al. 1995; Klerk et al. 2002), that catalyzes the irreversible reduction of 5,10methylenetetrahydrofolate to 5-methyltetrahydrofolate which acts as methyl donor for methionine synthesis from homocysteine (remethylation) (Goyette et al. 1998), also, mutations impairing this key enzyme are reported as causes of hyperhomocysteinemia (HHcyt) (Lievers et al. 2003 ), that is associated with increased risk for many disorders, including vascular and neurodegenerative diseases, pregnancy complications, cancers, etc. (Brustolin et al. 2010; Eloualid et al. 2012).

The 5, 10-MTHFR gene is located on chromosome 1 at 1p36.3. the complementary DNA sequence is 2.2 kilobases long and consists of 11 exons (Goyette et al. 1998), its several mutations including C677T (C to T) and A1298C (A to C) have been identified that decrease the MTHFR enzyme activity (Van der Put et al. 1995; Chen et al. 2005). These two single-nucleotide polymorphisms (SNPs) are the most frequent genetic cause for mild hyperhomocysteinemia (Frosst et al. 1995; Van der Put et al. 1995; Van der Put et al. 1998; Weisberg et al. 1998).

The C677T SNP results in a missense mutation, in exon 4 , that converts a cytosine $(\mathrm{C})$ into thymine $(\mathrm{T})$ which is leading to substitution of valine for alanine at position 222 (Kang et al. 1991; Frosst et al. 1995), renders the MTHFR enzyme thermolabile and less active (Frosst et al. 1995). A second polymorphism in the MTHFR gene is A1298C polymorphism, results from an adenosine to cytosine transversion, at nucleotide 1298, in exon (Weisberg et al. 2001; Lievers et al. 2003), which leads to substitution of Glutamate-429 by alanine (Frosst et al. 1995; Van der Put 
et al. 1998), this mutation can reduce the enzyme activity, although to lesser extent than the C677T polymorphism (Weisberg et al. 1998) and it does not affect the thermolability in the MTHFR gene (Van der Put et al. 1998). The coexistence of the double heterozygous (677CT/1298AC) individuals displays lower MTHFR activity than subjects heterozygous for either SNP (Van der Put et al.1998). Studies of ethnic groups around the world showed high variability in the allelic and genotypic distributions of the C677T and A1298C polymorphisms (Wilcken et al. 2003; Guéant-Rodriguez et al. 2006).

There are few studies and reports on the frequency of these two previous SNPs in Algerian population. The aim of this first study in Aures region, was to investigate the frequency of the MTHFR gene polymorphisms (C677T, $\mathrm{rs}=1801133 / \mathrm{A} 1298 \mathrm{C}, \quad \mathrm{rs}=1801131)$, as well as their coexistence in healthy subjects from this area (Northeast of Algeria), and compare the results with data reported from other ethnic populations.

\section{MATERIALS AND METHODS}

\section{Subjects}

A total of ninety-four healthy unrelated subjects, were volunteered to participate in this study (64 males with mean age $29.46 \pm 15.68$ and 30 females with mean age $43.03 \pm 15.28$ living in Aures region), and were recruited, after obtaining their informed consent. The mean age of the subjects studied was $33.79 \pm 16.72$ years, range [18-83 years].

\section{Blood collection and laboratory analysis}

Venous blood samples were collected in EDTA anticoagulant tube $(5 \mathrm{ml})$ and centrifuged immediately to isolate the cell pellets and plasma in separate tubes, the aliquots were stored at $-20^{\circ} \mathrm{C}$ until analyzed. This first step serves for the isolation of DNA from leukocytes.

\section{DNA extraction}

Genetic analyzes was performed at the CHU of Nancy (France), in the Laboratory of Nutrition-Genetics and Environmental Risk Exposure. Genomic DNA was extracted from blood leukocytes using the Kit BACC3 NUCLEON ${ }^{\circledR}$ marketed by Amersham Biosciences (Little Chalfont, UK). DNA extraction was performed according to the manufacturer's instructions.

\section{Molecular genetic analysis}

The MTHFR C677T, and A1298C and genotypes were determined using the Real-Time Polymerase Chain Reaction-fluorescence resonance energy transfer (RealTime PCR-FRET), it was carried out with a Light Cycler ${ }^{\circledR}$ 480 II Instrument (Roche Diagnostic, Meylan, France). (Ririe et al. 1997; Vossen et al. 2009).

The PCR primers and probes used in the assay and probe are: (i) For the C677T polymorphism: Sequence of primers Forward (F): 5'TGGCAGGTTACCCCAAAGG 3', Reverse primer (R): 5'TGATGCCCATGTCGGTGC3'. Probe Flu:
TGAGGCTGACCTGAAGCACTTGAAGGAGAAGGTG TCTX. Probe Red (LC Red): CGGGAGCCGATTTCATCAT p. (ii) For the A1298C polymorphism: Sequence of primers Forward (F): 5'CTTTTGGGAGCTGAAGGACTACTAC3'. Reverse primer (R): 5'CACTTTGTGACCATTCCGGTTTG 3'. Prob Flu: AAGGAGGAGCTGCTGAAGATGTGGGG GGAGGAGC TX. Prob Red (LC Red): ACCAGTGAAGAAAGTGTCTTTGAp.

The amplification conditions were as follows: PCR comprise an initial denaturation cycle at $95{ }^{\circ} \mathrm{C}$ for 10 seconds, followed by 40 cycles of PCR, each comprising denaturation at $95{ }^{\circ} \mathrm{C}$, hybridization at $55{ }^{\circ} \mathrm{C}$ and elongation at $72{ }^{\circ} \mathrm{C}$ for 10 seconds, 5 seconds, 5 seconds respectively, and finally cooling to $40^{\circ} \mathrm{C}$ for 30 seconds. (i) The melting temperatures for the three genotypes of MTHFR1 C677T are respectively: Wild genotype (CC): $63^{\circ} \mathrm{C}$; homozygous mutated (TT): $55^{\circ} \mathrm{C}$; heterozygous (CT): $55^{\circ} \mathrm{C}+64^{\circ} \mathrm{C}$. (ii) The melting temperatures for the three genotypes of MTHFR2 A1298C are respectively: Wild genotype (AA): $63^{\circ} \mathrm{C}$; homozygous mutated (CC): $60^{\circ} \mathrm{C}$; heterozygous (AC): $61^{\circ} \mathrm{C}$.

The data were expressed as a percentage for both allelic and genotypic frequencies. Pearson Chi-square test was used to compare different genotypes regarding gender (sex) characteristics. Data were analyzed using Statistical Package for the Social Sciences (SPSS) (Version 23.0.0.02015 for Windows, SPSS Inc., Chicago, IL). tics. $\mathrm{P}<0.05$ was considered to be statistically significant.

\section{RESULTS AND DISCUSSION}

\section{Allelic and genotypic frequencies of MTHFR C677T polymorphism}

We recruited ninety-four apparently healthy subjects, representing the Aures region in Algeria. Their mean age was $33.79 \pm 16.72$ years. This population was tested for C677T and A1298C MTHFR polymorphisms.

After Genotyping the 94 subjects, we found the wild type genotypes CC in $32(50 \%)$ males, and 12 females (40\%) among carriers of C677T MTHFR polymorphism, $24(37.5 \%)$ of males and $15(50 \%)$ of females were found to be heterozygous subjects, $8(12.5 \%)$ of males and 3 $(10 \%)$ of females were homozygous mutated, as shown in Table 1, the allelic frequency of the mutated $677 \mathrm{~T}$ allele was $40(31.25 \%)$ for males, and $21(35 \%)$ for females, and for $\mathrm{C}$ allele was $88(68.75 \%)$ for males, and $39(65 \%)$ for females. The most frequent genotype observed in men was the heterozygous $\mathrm{CC}$, followed by the homozygous $\mathrm{CT}$, the homozygous genotype TT had the lowest frequency, but in women, the first genotype was CT, then CC genotype and at last the TT genotype.

We compared the genotype and allelic frequencies of MTHFR C677T between the men subjects and women subjects, as reported in Table1. We did not find statistically significant differences in the percentage distributions of C677T MTHFR polymorphism between males and females carriers in this population $(\mathrm{P}=0.518)$. 
Table 1. The frequencies of genotypes and $\mathrm{C}, \mathrm{T}$ alleles among men and women carriers of C677T MTHFR polymorphism

\begin{tabular}{lcccc}
\hline & $\begin{array}{c}\text { Men } \\
(\mathbf{n}=\mathbf{6 4})\end{array}$ & $\begin{array}{c}\text { Women } \\
(\mathbf{n}=\mathbf{3 0})\end{array}$ & Total & P value \\
\hline Frequency & $\mathrm{N}(\%)$ & $\mathrm{N}(\%)$ & $\mathrm{N}(\%)$ & \\
Wild genotype CC & $32(50)$ & $12(40)$ & $44(46.48)$ & \\
Heterozygous CT & $24(37.5)$ & $15(50)$ & $39(41.8)$ & $0.518 \mathrm{a}$ \\
Homozygous TT & $8(12.5)$ & $3(10)$ & $11(11.70)$ & \\
& & & & \\
Allele C & $88(68.75)$ & $39(65)$ & $127(67.55)$ & \\
Allele T & $40(31.25)$ & $21(35)$ & $61(32.45)$ & \\
\hline
\end{tabular}

Note: ${ }^{\text {Pearson }}$ Chi-square test. $\mathrm{P}<0.05$ is statistically significant.

There are functional polymorphisms in genes encoding enzymes that may be associated with disease susceptibility. The MTHFR gene polymorphisms are among the most studied, however, two main variants from the functional point of view are the most studied: A1298C and C677T.

Although over the last few years C677T MTHFR polymorphism has been widely investigated, this is the first study that investigated the prevalence and the coexistence of MTHFR C677T and A1298C alleles and genotypes distribution in the Aures region population (Northeast Algeria).

The allele frequency of the C677T polymorphism varies across different geographical regions and ethnic groups (Wang et al. 2016). In this study, there were no significant differences in either the genotype distribution or allele between men and women $(\mathrm{P}=0.518)$, (Table 1). Our results provide further support that this frequency is not associated with gender, similar results were obtained in mainland China, a total of 88255 samples with reported C677T polymorphisms, based on all these samples, the authors did not find any difference between the males [19\% (12-25\%)] and females [21\% (19-24\%)] in terms of 677TTgenotype frequency (Wang et al. 2016). No difference in the MTHFR mutation frequency was also seen with respect to gender in Lebanese population (AL-Habboubi et al. 2003). A study of the C677T polymorphism frequency in 207 healthy subjects of Bosnian population, found that the Allele and genotype frequency of MTHFR C677T did not differ between males and females carriers $(\mathrm{P}=0.35)$ (Amela et al. 2013). In contrast, another study about Lebanese healthy subjects, showed statistical significance correlated to gender $(\mathrm{P}=0.012)$ (Amira et al. 2008).

There was some evidence for geographic gradients in Europe (north to south increase) in the prevalence of the TT homozygous genotype across the study areas, for example, the prevalence of the TT genotype was $4 \%$ in Finland and $7 \%$ in Russia, intermediate values (8-10\%) were noted in France and Hungary and higher values in southern Europe (12-15\% in Spain and northern Italy), peaking in southern Italy (20-26\% in Campania and Sicily) (Wilcken et al. 2003). Also, Nishio et al. (1996) reported that the prevalence of the TT genotype found in Germany was $(10.4 \%)$ and in Greece was (10.0\%).

A similar gradient has been observed in North America, where the frequency of TT genotype increases from western Canada (Alberta) to the south-eastern United
States (Atlanta), peaking in Mexico (Wilcken et al. 2003).

Another comparative study between Mexican, West African, and European populations, about the prevalence of the MTHFR C677T and A1298C alleles and folate status, found that the T677 allele frequency was highest in Mexico City, intermediate in eastern France and Sicily, and lowest in West Africa. The frequencies of the 677TT genotype and the 677T allele observed were as follows: in West Africa $(0.8-9.0 \%)$, in French (14.2-36.1\%), Italy (Sicily) (19.9$47.3 \%$ ) and Mexico City (35.7-58.0\%), an adequate folic acid intake has presumed enabled increase in the MTHFR $677 \mathrm{~T}$ frequency in these populations (Guéant-Rodriguez et al. 2006).

It is worth mentioning that in South-East Asian communities the prevalence of TT genotype was; $(12.0 \%)$ in South Korea, (11.0\%) in Japan (Nishio et al. 1996), and $(6.9 \%)$ in Taiwan (Wassim et al. 2004).

Across all 23 of the studied provinces, Wang et al. (2016) observed increases in the 677T allele and 677TT genotype frequencies along the geographical gradient, in the southern-central-northern direction across Mainland, from lower values, to intermediate, to higher values respectively. The frequencies of the $677 \mathrm{TT}$ genotype and the $677 \mathrm{~T}$ allele were: $7 \%(5-8 \%)$ and $25 \%(23-27 \%)$ in southern, $19 \%(16-21 \%)$ and $41 \%(36-45 \%)$ in central, and $28 \%(25-31 \%)$ and 53\% (51-55\%) in northern China (all P values $\leq 0.001)$. One such nutritional investigation revealed that the geometric mean of the blood folate concentration is lower in the northern populations than the southern populations (Hao et al. 2003).

In Indian study results showed wide variations, with the highest frequency of the $677 \mathrm{~T}$ allele among the Sindhi population $(23.8 \%)$. In contrast, the $677 \mathrm{~T}$ allele is absent in the Kom, Thadou and Munda populations, and its average frequency is $10.1 \%$ across all 23 populations in India (Saraswathy et al. 2012). The lower frequency of the $677 \mathrm{~T}$ allele among the tribal groups (the Kom, Thadou and Munda populations) may have been influenced by folate deficiencies because the majority of the population in India were vegetarians with low intake of vitamin $\mathrm{B}_{12}$ (Wang et al. 2016).

In another evaluation of Colombian individuals, healthy subjects were included, different genotype frequencies were found relative to the present report: the most frequently observed genotype was the heterozygous $\mathrm{C} / \mathrm{T}$ ( 80 individuals, $52.6 \%$ ), followed by the homozygous $\mathrm{C} / \mathrm{C}$ with 52 individuals $(34.2 \%)$ and $\mathrm{T} / \mathrm{T}$ had the lowest frequency in the population studied (20 individuals, 13.2\%) (Romero-Sánchez et al. 2015).

According to a study published on the association between C677T and A1298C polymorphisms and elevated homocysteine, in 117 healthy volunteers in Portugal population (southwestern Europe), that reported the distribution of the genotype and allele frequencies of C677T polymorphism was $33.3 \%$ for $\mathrm{T}$ allele and $66.7 \%$ for $\mathrm{C}$ allele. Overall, $10.3 \%$ of the subjects carried the $677 \mathrm{TT}$ genotype; the heterozygous status was $46.2 \%$, and $43.6 \%$ for the homozygous status. Therefore, these results show relative frequencies of the $677 \mathrm{~T}$ allele and of the $677 \mathrm{TT}$ genotype lower than those reported for the other 
two South European countries, Spain and Italy, and are not consistent with the idea of a north-south gradient, and confirm the notion that local geographic population studies are necessary (Castro et al. 2003).

An important study comprised of 408 healthy Lebanese and 152 healthy Bahraini subjects, found that the carriers $159(39.0 \%)$ Lebanese and $26(17.1 \%)$ Bahraini carriers were heterozygote, while $10(2.50 \%)$ Lebanese and 4 $(2.63 \%)$ were in the homozygous state (TT genotype) which are relatively low (Al-Habboubi et al. 2003). Another Lebanese study about healthy subjects, where the authors investigated the prevalence of MTHFR C677T polymorphism. The distribution of $\mathrm{CC}, \mathrm{CT}$, and TT genotypes found was, respectively: $65.3 \%, 30.8 \%$, and $3.9 \%$, with an overall carrier rate of $34.6 \%$ and allelic frequency of 0.19 (Saraswathy et al. 2012). In Jordanian population, Eid and Rihani (2004) reported that the TT genotype frequency was 8 and T allele frequency was 0.16 . These values are lower than observed in our study.

A few studies in the Arab Maghreb region have examined the MTHFR C677T polymorphism. In Morocco, based on this study that concerned 182 peoples apparently healthy and randomly selected in Arabs and Berbers Moroccan individuals, the following genotypes frequency of C677Tpolymorphism were found: CC genotype in 97 (53.3\%), CT genotype in $74(40.7 \%)$, TT genotype in 11 (6\%), the $\mathrm{T}$ allele was $(26.4 \%)$ (Paluku They-They et al. 2009). A study in Tunisia, which aims to determine the allelic and genotypic frequencies of the C677T polymorphism among a Tunisian healthy population, showed the following results: CC (69.7\%), CT (24.9\%), and TT $(5.4 \%)$. The frequency of the $\mathrm{T}$ allele estimated in the sample of 185 individuals was 17.8. These values are intermediate between those observed in Africa and those observed in Western countries (Jerbi et al. 2005). Bourouba et al. (2009) showed in healthy populations in Setif city (Algeria), that MTHFR 677CC genotype was found in 67 $(45.6 \%)$ individuals; 59 individuals were heterozygous (40.1\%), and 21 were homozygous (TT: $14.3 \%$ ). The frequency of MTHFR $677 \mathrm{~T}$ was found to be $34.3 \%$. These values remain intermediate between those observed in Africa and those observed in the West and in South America. An evaluation of the genotypic and allelic frequencies of C677T polymorphism on 100 healthy Algerian people, showed the following results: $\mathrm{C}$ allele (69.5\%), T allele (30.5\%), CC (45\%), CT (49\%), TT (6\%). Their study indicates an intermediate allelic frequency that joins the North-South world gradient with a high prevalence of Hyperhomocysteinemia (Hambaba et al. 2008). These last results are closely comparable to our outcomes achieved: T allele (32.45\%), TT (11.70\%).

In the present study, our findings corroborate those of other worldwide research, and are consistent with the hypothesis of a north-south gradient.

\section{Allelic and genotypic frequencies of MTHFR A1298C polymorphism}

The distribution of the MTHFR genotypes for the A1298C mutations is summarized in Table 2, the frequencies of AA, AC and CC genotypes of MTHFR A1298C polymorphism in males and females subgroup found as follows: [AA genotype for males; 39 (60.93\%), for females; 21 (70\%)], [AC genotype for male; 19 ( $29.68 \%)$, for females: 8 $(26.66 \%)], \quad[C C$ genotype for males; 6 (9.37\%), for females; 1 (3.33\%)], one women was detected with homozygous genotype (CC).

As shown previously in Table 2, the relative frequencies of the 1298A and1298C alleles in both males and females were [A Allele for males: 97 (75.78), for females: 50 (83.33)], [C Allele for males; 31 (24.21), for females: 10 (16.66)]. The same genotype frequency order's distribution was observed for A1298C polymorphism in both males and females; (firstly the AA genotype frequency, followed by $\mathrm{AC}$ genotype, and finally $\mathrm{CC}$ genotype). The carriers of wild-type allele homozygous (AA) genotype and heterozygous (AC) genotype were most represented in males than females; and the homozygous for the mutant allele (CC) genotype had the lowest frequency in women, $1(3.33) \%$.

We also did not find statistically significant differences in the percentage distributions of A1298C MTHFR polymorphism between men and women carriers in our group studied $(\mathrm{P}=0.514)$. Overall, in our analysis, 11 participants $(11.70 \%)$ of the subjects carried the $677 \mathrm{TT}$ genotype and 7 participants (7.44\%) had the $1298 \mathrm{CC}$ genotype. The heterozygous status for C677T mutations $(41.8 \%)$ was more frequent than the 1298 AC mutations $(28.72 \%)$.

The frequency distribution of the A1298C polymorphism is not as widely studied as the C677T polymorphism. Our results showed (Table 2) that no significant difference was found for both genders, in terms of carrier frequency $(\mathrm{p}=0.514)$. A study revealed that gender did not affect the distribution of the A1298C mutation since the frequencies of the genotypes are comparable between males and females $(p=0.618)$ (Amira et al. 2008).

Interesting study performed by researchers, showed that the West African countries and Mexico City were the 2 areas with the lowest frequencies of the $1298 \mathrm{C}$ allele and the1298CC genotype, and the highest frequency was reported in France. The $\mathrm{CC}$ genotype and $\mathrm{C}$ allele frequency observed was: in west Africa subjects $\mathrm{CC}$ (1.9\%), C (13.9\%), in Mexico city CC (2.3\%), C (14.7\%), in France CC $(11.5 \%), C(35.7 \%)$, in Italy (Sicily) such frequencies were CC (7.5\%) and C (28.1\%) (GuéantRodriguez et al. 2006). Of the 120 healthy Irish participants,

Table 2. The frequencies of genotypes and $\mathrm{C}, \mathrm{A}$ alleles among men and women carriers of A1298C MTHFR polymorphism

\begin{tabular}{lcccc}
\hline & $\begin{array}{c}\text { Men } \\
(\mathbf{n = 6 4 )}\end{array}$ & $\begin{array}{c}\text { Women } \\
(\mathbf{n}=\mathbf{3 0})\end{array}$ & Total & P value \\
\hline Frequency & $\mathrm{N}(\%)$ & $\mathrm{N}(\%)$ & $\mathrm{N}(\%)$ & \\
Wild genotype AA & $39(60.93)$ & $21(70)$ & $60(63.82)$ & \\
Heterozygous AC & $19(29.68)$ & $8(26.66)$ & $27(28.72)$ & $0.514^{\mathrm{a}}$ \\
Homozygous CC & $6(9.37)$ & $1(3.33)$ & $7(7.44)$ & \\
& & & & \\
Allele A & $97(75.78)$ & $50(83.33)$ & $147(78.19)$ & \\
Allele C & $31(24.21)$ & $(16.66)$ & $41(21.81)$ & \\
\hline
\end{tabular}

Note: ${ }^{a}$ Pearson Chi-square test. $\mathrm{P}<0.05$ is statistically significant. 
56 were heterozygous carriers, giving a genotype frequency of $46.7 \%$, whereas 11 (CC: $14.2 \%$ ) were homozygous for A1298C. The prevalence of 1298CC homozygotes in this Irish study is significantly higher than that reported for most European populations (Rita and Thomas 2004).

The frequencies in Turkey of MTHFR 1298AA, 1298 $\mathrm{AC}$, and $1298 \mathrm{CC}$ genotypes were $43.7 \%, 46.3 \%$, and $10.0 \%$, respectively (Sazci et al. 2005). Overall, the frequencies of the $1298 \mathrm{C}$ allele range from $24 \%$ to $40 \%$ in Europe, $0 \%$ to $15 \%$ in South America and $14.7 \%$ in North America (Amouzou et al. 2004). Lower frequencies were observed in Asian population CC (1.9\%) C (0.16) (Esfahani et al. 2003) and in Chinese population CC (3.8\%), C (0.176) (Shrubsole et al. 2004). However, it is crucial to note that in Lebanon which harbors the highest prevalence of the MTHFR A1298C polymorphism among different ethnic populations; the AC genotypic prevalence was $50.2 \%$ followed by the wild-type genotype AA, $25.9 \%$, and the homozygote genotype (CC) was (23.9\%), with an overall carrier rate of $74.14 \%$ and an allelic frequency of $\mathrm{C}$ 0.49 (the highest frequency) (Amira et al. 2008). In addition, the genotype frequency of $\mathrm{CC}$ and $\mathrm{C}$ allele was also higher among Tamilians population CC (10\%), C (0.35) (Angeline et al. 2004) and Bahraini Arabs (7.3\%), C (0.34) (Al-Habboubi et al. 2004). Indians population CC (3\%), C (0.10) (Markan et al. 2007) and Japanese CC (0.16), C (1.3\%) (Hiraoka et al. 2004), which scored the lowest values.

In the present study, our results appear lower CC (7.44\%), C (0.21), compared to the Arab's (Lebanese, Bahrain's Arabs) and Tamilians population. The A1298C allele frequency, although less documented, seems more uniform in the majority of the studied populations (Lievers et al. 2001; Peng et al. 2001; Weisberg et al. 2001). The association of the A1298C mutation with decreased MTHFR specific activity is agreed (Lievers et al. 2001). Different from C677T, the biochemical effect of the A1298C mutation on MTHFR function is still controversial (Van der Put et al. 1998; Friso et al. 2002), indeed the relationship between the gene polymorphisms MTHFR A1298C and Hcy levels remains controversial (Wang et al. 2017).

\section{The frequency of coexistence of MTHFR C677T and A 1298C polymorphisms}

The coexistence of genotypes of both mutations was examined and given in Table 3, our data showed that the most frequent coexistence genotypes were: $677 \mathrm{CC} /$ 1298AA (22.34\%), 677CT/1298AA (29.78\%), 677CC/ 1298AC (17.02\%) and the genotypes less frequent were: 677TT/1298AA (11.70\%), 677CT/1298AC (11.70\%), $677 \mathrm{CC} / 1298 \mathrm{CC}(7.44 \%)$, the 677TT genotype was associated with the wild type homozygous 1298AA genotype in all individuals, it's same case as 1298CC which always was associated with the wild type homozygous 677CC genotype.

In our study, the following genotypes: $677 \mathrm{TT} / 1298 \mathrm{AC}$, 677CT/1298CC, 677TT/1298CC (the homozygous double mutant) has been no observed.
Table 3. The frequency of coexistence of C677T and A 1298C polymorphisms

\begin{tabular}{llcccc}
\hline \multirow{2}{*}{ Genotypes } & \multicolumn{4}{c}{ C677T MTHFR } \\
\\
\cline { 3 - 5 } & & CC & CT & TT & Total \\
MTHFR & & 21 & 21 & 11 & 60 \\
& AC & 16 & 11 & 00 & $(63.82)$ \\
& & $(17.02)$ & $(11.70)$ & $(00.00)$ & $(28.72)$ \\
& CC & 07 & 00 & 00 & 7 \\
& & $(7.44)$ & $(00.00)$ & $(00.00)$ & $(7.44)$ \\
& Total & 44 & 39 & 11 & 94 \\
& & $(46.80)$ & $(41.48)$ & $(11.70)$ & $(100.00)$ \\
\hline
\end{tabular}

Table 4. MTHFR activity (\%) according to the presence of C677T and A1298C polymorphisms (Van der Put et al. 1998; Weisberg et al. 1998)

\begin{tabular}{llccc}
\hline \multirow{2}{*}{ Genotypes } & & \multicolumn{3}{c}{ C677T MTHFR } \\
& & CC (\%) & CT (\%) & TT (\%) \\
\hline A1298C & AA (\%) & 100 & $60-70$ & $30-40$ \\
MTHFR & AC (\%) & $79-80$ & $50-60$ & - \\
& CC (\%) & $50-60$ & - & - \\
\hline
\end{tabular}

Few studies have anchored their analyses in examination of the coexistence of C677T and A1298C variants in different populations, and their correlation with MTHFR activity and folate level change (GuéantRodriguez et al. 2006). One of the first studies was performed on the Dutch population (Van der Put et al.1998), the study did not found the coexistence of the 677CT/1298CC, 677TT/1298AC, 677TT/1298CC genotypes, similar results obtained in our studied group (Table 3), and in several European studies. A less frequent coexistence genotypes 677TT/1298AA (9\%), $677 \mathrm{CC} / 1298 \mathrm{CC}(9.4 \%)$ was found in the Dutch population, comparable to our results: 677TT/1298AA (11.70\%), $677 \mathrm{CC} / 1298 \mathrm{CC}(7.44 \%)$. The most frequent coexistence genotypes 677CT/1298AA (20.1\%), as well as found in our group 677CT/1298AA (29.78\%), whereas 677CT/1298AC (20.1\%), was detected low common in our study (11.70\%), equally the 677TT/1298AA genotypes were noted low in our population $(11.70 \%)$.

An exploration of MTHFR activity's according to the presence of C677T and A1298C polymorphisms are shown in Table 4 above (Van der Put et al.1998; Weisberg et al.1998). The authors revealed a significant decrease of the MTHFR activity in cases of coexistence of the genotypes MTHFR 677TT/1298AA (30-40\%, approximately 70\% less active), 50\% decrease of MTHFR activity was observed in 677CT/1298AC genotypes. Nearly 40\% reduction in enzyme activity was observed in the other genotypes (677CC/1298CC, 677CT/1298AA).

Contrary to our results, exceptional cases were reported in Turkish population observed a coexistence of 677CT/1298CC, 677TT/1298AC (Ergul et al. 2003; Sazci et al. 2005). In one of these two studies, which involved 1004 women and 680 men (1684), the frequency of double heterozygous genotypes was 677CT/1298AC (21.6\%) (Sazci et al. 2005). Interestingly, 677TT/1298AC was 
detected also in Hundo population (Kumar Rai et al. 2006), and equally it was detected in Canada by Isotalo et al. (2000) who studied 119 Canadians newborns; TT/AC: 2 $(1.70 \%)$, for the others coexisting genotypes, they were as follow: CC/AA: 17 (14.30\%), CC/AC: 42 (35.30\%), CC/CC: 9 (7.60\%), CT/AA: 14 (11.70\%), CT/AC: 23 (19.30\%), TT/AA: $12(10.10 \%)$, TT/CC and CT/CC genotypes were not observed in this study.

De Re et al. 2010 demonstrated the coexistence of the $677 \mathrm{CT} / 1298 \mathrm{AC}$ in $(30.20 \%)$ of 454 Italian subjects $(315$ men and 139 women). In Irish population study of the MTHFR C677T/A1298C genotype combinations, 28 participants $(23.3 \%)$ were double heterozygotes (Rita and Thomas 2004), another study population which consisted of 1684 randomized individuals from around Turkey, of whom 1004 were females and 680 were males the frequency of $\mathrm{C} 677 \mathrm{~T} / \mathrm{A} 1298 \mathrm{C}$ compound heterozygosity is highest in Turkey $(21.6 \%)$, as compared to Canada (15\%), the United States (17\%) and the Netherlands (20\%) (Sazci et al. 2005), this results were most frequent than those obtained in our analysis (11.70\%). Also, 677TT/1298AA genotypes were found in (12.60\%) by (De Re et al. 2010), results were similar to those achieved in our study $(11.70 \%)$. A study investigated the frequency of these two MTHFR polymorphisms in a Portuguese population, in 117 healthy volunteers (71 females, 46 males) studied, 21.4\% of the subjects were compound heterozygotes for the two MTHFR SNPs (677CT/1298AC), the 1298C allele frequency was $28.2 \%$, demonstrating that the mutation is also common in this population (Castro et al. 2003).

Noteworthy, a higher frequency of the coexistences of genotypes with the mutated allele suggested a significant role of diet rich in folate in the south of Europe (Italy, Turkey) that could affect an individual's ability to survive with mutated genotypes of MTHFR polymorphisms (Hubert et al. 2015). It appears that C677T and A1298C polymorphisms can act synergistically, given that heterozygosity for both polymorphisms causes lower MTHFR activity than heterozygosity alone for either mutation (Van der Put et al. 1998). Also, an association of double heterozygote status with elevated tHcy levels in the presence of low folate status was observed (Van der Put et al. 1998). Previous studies have proved that the A1298C polymorphism in combination with $\mathrm{C} 677 \mathrm{~T}$ appeared to affect enzyme activity and tHcy (Weisberg et al. 1998; Weisberg et al. 2001). However, other authors failed to find any influence of folate on the distribution of the $677 \mathrm{CT} / 1298 \mathrm{AC}$ combined genotype in the 7 areas studied; West Africa, coastal and savannah areas of Togo, coastal Benin, France, Sicily, and Mexico City (Guéant-Rodriguez et al. 2006).

In conclusion, this study is the first to report frequency and the coexistence of C677Tand A1298C MTHFR polymorphisms in healthy Algerian population (Aures region). For the C677T SNP, our intermediate data were agreed with the hypothesis of a North-South gradient. The $\mathrm{C}$ allele and CC genotype frequencies of the A1298C polymorphism was found lower; CC (7.44\%), C (0.21) compared to ethnic groups; this SNP has not been extensively studied worldwide and in Algeria particularly.
The Coexistence of C677T and A1298C MTHFR polymorphisms genotypes observed in this study is consistent with the data from literature with lower frequency of the double heterozygotes (677CT/1298AC: $11.70 \%)$. Analysing the combination genotypes of the two SNPs in Algerian population is also an important point should be raised. Furthers studies in MTHFR gene polymorphisms are needed to clarify their possible impact on public health in Aures region (Northeast Algeria).

\section{ACKNOWLEDGEMENTS}

We would like to extend our gratitude and appreciation to Professor Rosa-Maria Guéant-Rodriguez, Professor Jean-Louis Guéant, all personnel of the Nutrition-GeneticsEnvironmental Risk Exposure Laboratory, Nancy (France) for the technical assistance to the carrying out this important work.

\section{REFERENCES}

Al-Habboubi H, Tamim H, Ameen G, Almawi WY. 2004. C677T and A1298C single nucleotide polymorphisms in the methylenetetrahydrofolate reductase gene among Bahraini Arabs. Thromb Haemost 91: 843-845.

AL-Habboubi H, Tamim H, Ameen G, Almawi WY.2003. A common mutation in 5,10-Methylentetrahydrofolate reductase (MTHFR) gene in two Arab communities. J Throm Haemost 1: 2246-8.

Amela K, Rifet T, Zoran J, Jasminka MM. 2013.The Frequency of C677T Methylenetetrahydrofolate Reductase (MTHFR) Polymorphism in Southern East Bosnian Population. J Biomet Biostat 4: 169.

Amira S, Ziyad M, Ali T, Ghazi Z, Rose D, Rami AA M. 2008. High Prevalence of MTHFR Gene A1298C Polymorphism in Lebanon. Mary Ann Liebert Inc 6: 75-80.

Amouzou EK, Chabi NW, Adjalla CE, Rodriguez-Guéant RM, Feillet F, Villaume C, Sanni A, Guéant JL. 2004. High prevalence of hyperhomocysteinemia related to folate deficiency and the $677 \mathrm{C}->\mathrm{T}$ mutation of the gene encoding methylenetetrahydrofolate reductase in coastal West Africa. Am J Clin Nutr 79: 619-24.

Angeline T, Jeyaraj N, Granito S, Tsongalis GJ. 2004. Prevalence of MTHFR gene polymorphisms (C677T and A1298C) among Tamilians. Exp Mol Pathol 77: 85-88.

Bourouba R, Houcher B, Djabi F, Eğin Y, Akar N. 2009. The Prevalence of Methylenetetrahydrofolate Reductase 677 C-T, Factor V 1691 GA, and Prothrombin 20210 G-A Mutations in Healthy Populations in Sétif, Algeria. Clin Appl Thromb Hemost 5: 529-534.

Brustolin S, Giugliani R, Felix TM. 2010. Genetics of homocysteine metabolism and associated disorders. Braz J Med Biol Res 43: 1-7.

Castro R, Rivera I, Ravasco P, Jakobs C, Blom HJ, Camilo ME, de Almeida IT. 2003. 10-Methylenetetrahydrofolate reductase $677 \mathrm{C}->\mathrm{T}$ and 1298A-> C mutations are genetic determinants of elevated homocysteine. Q J Med 96: 297-303.

Chen M, Xia B, Rodriguez-Gueant RM, Bigard M, Gueant J-L. 2005. Genotypes $677 \mathrm{TT}$ and $677 \mathrm{CT}+1298 \mathrm{AC}$ of methylenetetrahydrofolate reductase are associated with the severity of ulcerative colitis in central China. Gut 54: 733-734

De ReV, Cannizzaro R, Canzonieri V, Cecchin E, Caggiari L, De Mattia E, Pratesi C, De Paoli P, Toffoli G. 2010. MTHFR polymorphisms in gastric cancer and in first degree relatives of patients with gastric cancer. Tomor Biol 31: 23-32.

Eid SS, Rihani G. 2004. Prevalence of factor V Leiden, prothrombin G20210A, and MTHFR C677T mutations in 200 healthy Jordanians. Clin Lab Sci 17: 200-202.

Eloualid A, Abidi O, Charif M, El houate B, Benrahma H, Louanjli N, Chadli E, Ajjemami M, Barakat A, Bashamboo A, McElreavey K, Rhaissi H, Rouba H. 2012. Association of the MTHFR A1298C variant with unexplained severe male infertility. PLoS One 7: e34111. DOI: 10.1371/journal.pone.0034111. 
Ergul E, Sazci A, Utkan N, Canturk Z. 2003. Polymorphisms in the MTHFR gene are associated with breast cancer. Tumor Biol 24: 286290.

Esfahani ST, Cogger EA, Caudill MA. 2003. Heterogeneity in the prevalence of methylene-tetrahydro-folate reductase gene polymorphism in women of different ethnic groups. J Am Diet Assoc 103: 200-207.

Friso S, Girelli D, Trabetti E, Stranieri C, Olivieri O, Tinazzi E, Martinelli N, Faccini G, Pignatti PF, Corrocher R et al. 2002. A1298C methylenetetrahydrofolate reductase mutation and coronary artery disease: relationships with $\mathrm{C} 677 \mathrm{~T}$ polymorphism and homocysteine/folate metabolism. Clin Exp Med 2: 7-12.

Frosst P, Blom HJ, Milos R, Goyette P, Sheppard CA, Matthews RG, Boers GJH, den Heijer M, Kluijtmans LAJ, van den Heuvel LP, Rozen R. 1995. A candidate genetic risk factor for vascular disease: a common mutation in methylenetetrahydrofolate reductase. Nat Genet 10: 111-113.

Goyette P, Pai A, Milos R, Frosst P, Tran P. 1998. Gene structure of human and mouse methylene-tetrahydrofolate reductase (MTHFR). Mamm Genome 9: 652-656.

Guéant-Rodriguez RM, Guéant JL, Debard R, Thirion S, Hong LX, Bronowicki JP, Namour F, Chabi NW, Sanni A, Anello G, Bosco P Romano C, Amouzou E, Arrieta HR, Sánchez BE, Romano A, Herbeth B, Guilland JC, Mutchinick OM. 2006. Prevalence of methylenetetrahydrofolate reductase $677 \mathrm{~T}$ and $1298 \mathrm{C}$ alleles and folate status: a comparative study in Mexican, West African, and European populations. Am J Clin Nutr 83 (3): 701-707.

Hambaba L, Abdessemed S, Yahia M, Laroui S, Rouabahal F. 2008. Relation entre hyperhomocystéinémie et polymorphisme C677T du gène de la méthylène tétrahydrofolate réductase dans la population algérienne saine. Ann Biol Clin 66: 637-41.

Hao L, Ma J, Stampfer MJ, Ren A, Tian Y, Tang Y, Willett WC, Li Z. 2003.Geographical, seasonal and gender differences in folate status among Chinese adults. J Nutr 133 (11): 3630-3635.

Hiraoka M, Kato K, Saito Y, Yasuda K, Kagawa Y. 2004. Gene-nutrient and gene-gene interactions of controlled folate intake by Japanese women. Biochem Biophys Res Commun 316: 1210-1216.

Hubert W, Maria K, Aleksandra E M, Magdalena B, Grażyna K. 2015. Coexistence of the $677 \mathrm{C}>\mathrm{T}$ and A1298C MTHFR polymorphisms and its significance in the population of Polish women. Ginekol Pol 86: $742-747$

Isotalo PA, Wells GA, Donnelly JG. 2000. Neonatal and fetal methylenetetrahydrofolate reductase genetic polymorphisms: An Examination of C677T and A1298C Mutations. Am J Hum Genet 67-986-990.

Jerbi Z, Abdennebi M, Douik H, Ben Romdhane H, Harzallah L, Guemira F, Ghanem A. 2005. Étude du polymorphisme C677T du gène de la méthylène tétrahydrofolate réductase dans la population tunisienne. Ann Biol Clin 63: 487-491.

Kang SS, Wong PW, Susmano A, Sora J, Norusis M, Ruggie N 1991.Thermolabile methylenetetrahydrofolate reductase: an inherited risk factor for coronary artery disease. Am J Hum Genet 48: 536-545.

Klerk M, Verhoef P, Clarke R, Blom HJ, Kok FJ, Schouten EG.2002. MTHFR Studies Collaboration Group. MTHFR 677C-> T polymorphism and risk of coronary heart disease: a meta-analysis. $\mathrm{J}$ Am Med Assoc 288: 2023-2031.

Lievers KJ, Boers GH, Verhoef P, den Heijer M, Kluijtmans LA, van der Put NM, Trijbels FJ, Blom HJ. 2001. A second common variant in the methylenetetrahydrofolate reductase (MTHFR) gene and its relationship to MTHFR enzyme activity, homocysteine, and cardiovascular disease risk. J Mol Med 79: 522-528.

Lievers KJA, Kluijtmans LJA, Blom HJ. 2003. Genetics of hyperhomocysteinemia in cardiovascular disease. Ann Clin Biochem 40: 46-59.

Lim HS, Heo YR. 2002. Plasma total homocysteine, folate, and vitamin B12 status in Korean adults. J Nutr Sci Vitaminol 48: 290-297.

Malinow MR. 1994.Homocysteine and arterial occlusive diseases. J Intern Med 53: 603-607.

Markan S, Sachdeva M, Sehrawat BS, Kumari S, Jain S, Khullar M. 2007. MTHFR 677 CT/MTHFR 1298 CC genotypes are associated with increased risk of hypertension in Indians. Mol Cell Biochem 302: $125-131$

Nishio H, Lee MJ, Fujil M, Kario K, Kayaba K, Shimada K, Matsuo M, Sumino K.1996.A common mutation in methylenetetrahydrofolate reductase gene among the Japanese population. JPN Am J Hematol 41 (2): 247-251.

Paluku They-They T, Hamzi K, Mazabraud A, Nadifi S. 2009. Fréquence du polymorphisme C677T du gène de la méthylène tetrahydrofolate réductase (MTHFR) dans les populations arabe et berbère du Maroc. Antropo 20: 11-17.

Peng F, Labelle LA, Rainey BJ, Tsongalis GJ. 2001. Single nucleotide polymorphisms in the methylenetetrahydrofolate reductase gene are common in US Caucasian and Hispanic American populations. Int $\mathrm{J}$ Mol Med 8: 509-511.

Rai AK, Sigh S, Mehta S, Kumar A, Pandey LK, Raman R. 2006. MTHFR C677T and A1298C polymorphisms are risk factors for Down's syndrome in Indian mothers. J Hum Genet 51: 278-283.

Ririe KM, Rasmussen RP, Wittwer CT. 1997. Product differentiation by analysis of DNA melting curves during the polymerase chain reaction. Anal Biochem 245: 154-160

Rita K, Thomas R. 2004. Increased Frequency of the MTHFR A1298C Mutation in an Irish Population. Clinchem. 50, No. 12. DOI: 10.1373/clinchem.2004.038158.

Romero-Sánchez C, Gómez-Gutierrez A, Gómez PE, Casas-Gomez MC, Briceño I. 2015. C677T (rs1801133) MTFHR gene polymorphism frequency in a colombian population. Colomb Med 46: 75-79.

Saraswathy KN, Asghar M, Samtani R, Murry B, Mondal PR, Ghosh PK, Sachdeva MP. 2012. Spectrum of MTHFR gene SNPs C677T and A1298C: a study among 23 population groups of India. Mol Biol Rep 39 (4): 5025-5031.

Sazci A, Ergul E, Kaya G, Karat I. 2005. Genotype of allele frequencies of the polymorphic methylenetetrahydrofolate reductase gene in Turkey. Cell Biochem Funct 23: 51-54.

Shrubsole MJ, Gao YT, Cai Q, Shu XO, Dai Q, Hebert JR, Jin F, Zheng W. 2004. MTHFR polymorphisms, dietary folate intake, and breast cancer risk: results from the Shanghai Breast Cancer Study. Cancer Epidemiol Biomarkers Prev 13: 190-196.

Taguchi T, Mori H, Hamada A, Yamori Y, Mori M. 2012. Serum folate, total homocysteine levels, and methylenetetrahydrofolate reductase $677 \mathrm{C}>\mathrm{T}$ polymorphism in young healthy female Japanese. Asia Pac J Clin Nutr 21: 291-295.

Van der Put NM, Gabreëls F, Stevens EM, Smeitink JA, Trijbels FJ, Eskes TK, van den Heuvel LP, Blom HJ. 1998. A second common mutation in the methylenetetrahydrofolate reductase gene: an additional risk factor for neural-tube defects?. Am J Hum Genet 62: 1044-1051.

Van der Put NM, Steegers-Theunissen RP, Frosst P, Trijbels FJ, Eskes TK, van den Heuvel LP, Mariman EC, den Heyer M, Rozen R, Blom HJ. 1995. Mutated methylenetetrahydrofolate reductase as a risk factor for spina bifida. Lancet 346: 1070-1071.

Vossen R, Aten E, Roos A, Dunnen J T. 2009. High-Resolution Melting Analysis (HRMA)-More than just a sequence variant screening. Human Mutation 30: 860-866.

Wang J, Ouyang N, Qu L, Lin T, Zhang X, Yu Y, Jiang C, Xie L, Wang L, Wang Z, Ren S, Chen S, Huang J, Liu F, Huang W, Qin X. 2017. Effect of MTHFR A1298C and MTRR A66G genetic mutations on homocysteine levels in the Chinese population: a systematic review and meta-analysis. J Transl Intern Med 5: 220-229.

Wang X, Fu J, Li Q, Zeng D. 2016. Geographical and Ethnic Distributions of the MTHFR C677T, A1298C and MTRR A66G Gene Polymorphisms in Chinese Populations: A Meta Analysis. PLoS One11: e0152414. DOI: 10.1371/journal.pone.0152414

Wassim YA, Ramzi RF, Hala T, Jocelyn LD, Noha IH. 2004.Differences in the Frequency of the C677T Mutation in the Methylenetetrahydrofolate Reductase (MTHFR) Gene among the Lebanese Population. Am J Hematol 76: 85-87.

Weisberg I, Tran P, Christensen B, Sibani S, Rozen R.1998. A second genetic polymorphism in methylenetetrahydrofolate reductase (MTHFR) associated with decreased enzyme activity. Mol Genet Metab 64: 169-172.

Weisberg IS, Jacques PF, Selhub J, Bostom AG, Chen Z, Curtis Ellison R, Eckfeldt JH, Rozen R. 2001. The 1298ARC polymorphism in methylenetetrahydrofolate reductase (MTHFR): in vitro expression and association with homocysteine. Atherosclerosis 156: 409-415.

Wilcken B, Bamforth F, Li Z, Zhu H, Ritvanen A, Renlund M, Stoll C, Alembik Y, Dott B, Czeizel AE, Gelman-Kohan Z, Scarano G, Bianca S, Ettore G, Tenconi R, Bellato S, Scala I, Mutchinick OM, López MA, de Walle H, Hofstra R, Joutchenko L, Kavteladze L, Bermejo E, Martínez-Frías ML, Gallagher M, Erickson JD, Vollset SE, Mastroiacovo P, Andria G, Botto LD. 2003. Geographical and ethnic variation of the $677 \mathrm{C}>\mathrm{T}$ allele of 5,10 methylenetetrahydrofolate reductase (MTHFR): findings from over 7000 newborns from 16 areas worldwide. J Med Genet 40: (8) 619-625. 